\title{
VI
}

\section{THE NATURE AND CAUSE OF PHOBIAS, WITH SPECIAL REFERENCE TO SYPHILOPHOBIA*}

\author{
By Dr. J. A. HADFIELD, M.B., Ch.B.Ed.
}

Mr. President, Ladies and Gentlemen,-I feel, in the first place, that I owe this audience an apology because, as I explained to Dr. Clarkson, I have had very few cases of syphilophobia in my practice, but those I have had are in no essential respect different from the ordinary phobias of which one meets instances in ordinary psychological practice. Therefore, using the one or two cases of syphilophobia which I have had as illustrations, I suggest that I deal with the general question of the causal origin of phobias, with especial reference to syphilophobia, because before we can understand the latter we need to understand the psychopathology of phobias in general.

We are familiar with the different types of phobia met with in ordinary life every day; there are the common fears, like agoraphobia, i.e., the fear of open spaces, which really is a fear of isolation and loneliness; there is the fear of closed spaces, which prevents people travelling in Tubes. And there is another type of fear in which there is a fear of harm to other people rather than to the person who experiences it, such as the wife who is perpetually afraid that an accident will happen to her husband, or the man who had the impulse to strangle any girl he was in love with, so that he had to break off engagements, or the fear of the husband that while he is at the dinner table he will stab his wife with the knife. These latter I prefer to call aggressions.

Another kind is that in which people have propitiations; they feel an urge to carry out ceremonial or propitiatory acts, such as stepping over the junctions of paving stones, or saying their prayers several times before getting into bed, or insisting in putting knives and forks straight

* Based on an address delivered before the Medical Society for the Study of Venereal Diseases, April 2nd, r937. 


\section{BRITISH JOURNAL OF VENEREAL DISEASES}

when sitting down to table. These are cases of obsessions, and are akin to the phobias and anxiety states.

Characteristics of all these phobias are (I) that they are involuntary, i.e., the patient or person does not willingly do these things. He finds doing them is a nuisance, but he is compelled to perform this ritual because if he does not do so he gets into a state of restlessness. (2) They are compulsive, he feels himself forced to do these things. If the force is fear it is a compulsive fear, which seizes his whole personality. (3) They are irrational, and the patient recognises that they are so; he recognises that the Tube, or loneliness, is not adequate to produce the fear. That is a very important factor in the psychopathology of these conditions, especially from the points of view of treatment and prognosis, as it differentiates the obsessions from the psychotic delusions. A man may fear he has got syphilis but agrees it is stupid, as he has many times been reassured that he has not got it. But the person who suffers from a psychotic delusion believes in the validity of the delusion; he believes he has got syphilis, or that some awful thing will happen to him, and he is obsessed by the impulse, as in the case of the man who felt he must commit murder. This type of man will not co-operate in efforts to get him well, though he will take any amount of physical treatment. He will not recognise that he has got a mental illness.

We have to differentiate cases of true syphilophobia, of either kind, from those who fear that they have got syphilis and have a justifiable fear of it; such as the man who has exposed himself to that infection, in which case the fear is not irrational ; it is neither compulsive nor irrational. Some others who have a fear of syphilis are people of the temperamental, nervous type, who will readily fear anything in life. We do not need to deal with those; it is accidental whether the fear is of syphilis, or of cancer, or gastric ulcer.

What we want to discuss are cases of true obsessional fears, i.e., compulsive and irrational, and we shall exclude psychotic cases, as they are in a different category. These are, for the most part, constitutional, or temperamental, or toxic, and so the treatment is not on psychological lines.

So I shall speak only of those who have obsessional 
compulsions or irrational phobias. Even they are of different types clinically. There is the man who is afraid he has got syphilis, though he has not exposed himself to it, and he probably recognises the irrationality of his position. There is another group of those who have exposed themselves to infection, and have been examined and reassured several times that they have not got the disease, but still fear that they may have it. That is the most common type.

A third group are the people who have exposed themselves to infection and continue to do so, and who have these persistent fears that they will catch the infection. I have a case of that kind on hand now. We have to differentiate these to some extent, but they all come under the group of compulsions and obsessions.

With regard to the general question of the psychopathology of the phobias, we have admitted that these fears are entirely irrational, and that the supposed cause is an inadequate one. Therefore we must ask ourselves, What is it that the patient fears? First, these fears are never the fears of the objective situation upon which they are projected. Take the case of the agoraphobic: he is not really afraid of that open space; he projects his fear on to that, but it is not really the cause. In every case of obsession and phobia the fear is of himself. Sometimes the phrase is used, "He is afraid of his own shadow." A classic phrase is, " Conscience doth makes cowards of us all." That is very descriptive of the syphilophobiac; the sense of guilt causes the fear ; there is a fear of some forbidden impulse, the indulgence in which is fraught with dire consequences to ourselves. Sometimes the patient is unaware of any forbidden impulse in himself; all he knows is that he is suddenly seized with a panic of fear, which seems irrational, because in the past that impulse has been repressed, and therefore operates unconsciously. These people fear the impulse without knowing what is the cause of the fear.

But in some cases the impulse shows itself in consciousness. Take the case of the man who had the impulse to strangle a girl; he was consciously afraid of it. But he was unaware he had the wish to do so, and still less aware why he had that wish. It is only by analysing the condition back to its source that one can discover the reason of the impulse and the fear. In all obsessional phic bias, 
including syphilophobia, there is an essential conflict in the personality itself, and the conflict is between the selfwilled determination to do what one wants on one hand and the fear of the consequences on the other. Thus you get an endopsychic conflict, a fight in the personality between these two forces. So we can say that one part of the personality is self-willed, determined to do what it wants, and the other part of the personality says "If you do this, disaster will happen." That is the reason why fear is fear of the impulse itself. So whenever the impulse of a forbidden sexual impulse comes up, immediately the person has a terror and fear. Thus you see the truth of the phrase that every phobia represents a repressed desire.

Now I can mention to you a case of syphilophobia, which I have analysed, to bring out some points in the psychopathology of the condition. He was a professional man, and very intelligent, and he knew he had not got syphilis ; he had been examined and reassured, and yet he could not help being obsessed with the idea that he had it. Let us take his history in chronological order, which is not the order in which one analyses it. I found, as you practically always find in these anxiety cases, that there was a primary fear in the first year of life ; usually they start off with a terrible fear of life. He had a very cruel nurse, who ill-treated him and was herself very "religious"; she put the fear of God into him by punishing him in various ways. On the other hand, this treatment filled him with a great rage against her, which he had to repress because of his fear of her. He did what many infants do who are not given affection, he masturbated, he resorted to sex feelings as a solace in his depression. The nurse discovered him masturbating and threatened him violently. But at two years of age he continued to masturbate, in spite of her threats, and kept it up until he was six. At that age he was out with her one day and she told him to walk beside her, and he disobeyed, ran across the street, was knocked down, and his skull was fractured. He was unconscious a long time and nearly died. In that state the nurse insisted on his saying his prayers, and in his concussed and delirious state he feared he was going to die, and the Hell which had been promised him became a serious reality. He therefore determined that he must give up all disobedience and all sex indulgence, but it was under the impetus of fear. 


\section{THE NATURE AND CAUSE OF PHOBIAS}

When he grew up and went to the War his moral restraints were removed, and there was a return of the old selfwilled impulse and the former sexual desire and he started to go with women. Then he was filled with this terrible fear that he had got syphilis, which was the fear, exaggerated by his early experiences of his being selfwilled and disobedient. There is no justification for it, but the fear is tremendously exaggerated.

In all cases of phobia there is that essential conflict between the aggressive impulse and fear of consequences. In syphilophobia the aggressive self-will is of a sexual nature. Freud says there is always a sexual element in anxiety states, but I do not think it is so in such cases as that in which a man had the impulse to murder the girl.

Now, this self-will and fear are very common in children, so why do not all children get these states? In many cases if a child is told it will be punished if it does a certain thing it does not do it, it will not run the risk ; so there is no conflict. Some children are more assertive, they defy the fears and the threats, and determine to do what is prohibited when nobody is looking, and they have no mental conflict. Such may later on become a delinquent, because he feels himself to be an enemy of organised society.

In the case of the defiant, self-willed child, he tries to solve his problem in various ways. One is to make a pact with God, his parents and his conscience, and says, "I will be good in every other respect, but I will do that which I am forbidden." Such a child is conscientious and anxious to please his mother, but nearly always he has a sense of guilt because he is over-compensating for some forbidden impulse in himself. In another child the fear is so great that he is compelled to repress his self-will, so he represses his desires, but those desires are not obliterated. Therefore every time the impulse is aroused or stimulated this fear comes up in his mind.

In phobias we always find a primal fear in infancy, and only by analysis can we get at that. Often it originates in illness, such as broncho-pneumonia, or in fear of loneliness. In connection with agoraphobia, I think of the case of the child who was taken along a lonely beach in winter time by his nurse, who cruelly threatened him and took hold of his throat, and there 
was nobody near to give him succour. So, in that way, he associated fear with open spaces. The fear itself may pass away and may produce a reaction of opposite kind, an aggressiveness to compensate for a hidden fear; it is he who is unconsciously a coward who shows most bravado in times of danger to over-compensate for his fear. So we get the exaggerated self-will.

Sometimes the aggressive element is due to the child being a spoilt child; he gets the idea that he is a potentate or a dictator and can do as he likes. And that may lead to fears. You find this aggressive element in all phobias. A syphilophobiac may cling to you in a pleading, anxious way, and may not seem to be at all selfassertive, but he is always a person with what is known as a "power psychology," he wants his own way, and if he cannot get it otherwise he will get it through fear of illness. If an adult case is enquired into, husband or wife will say the patient insists on having his own way. It is shown in the course of analysis, because there are violent scenes of anger and resentment, jealousy and obstinacy.

Another reaction to fear, as in the case I gave you, is that of sex, because when these people are in a state of fear or repression, one way to find solace is resorting to auto-eroticism-sucking the thumb or masturbation. This becomes the one joy, a mental retreat from the world.

Then there arrives a time when the forbidden impulse is discovered and threats are uttered, for children are still told that if they masturbate they will be terribly ill-it is a common history in cases of syphilophobia-and nobody will love them and they will go to Hell. Statistics show that 90 per cent. of children masturbate in their first year of life. Now that the practice is regarded in a more natural way, cases of phobia of this kind are not likely to be so common in the future.

On account of this threat the sexual indulgence is repressed and there is an effort to observe moral standards so as to get the approval of society. Later, when the person arrives at puberty, he breaks away from this standard and yields to temptation, and this arouses again the previous fear; and although there is now some rationality in it, the old threat of dire disease returns. Some have a fear of syphilis though they have never had contact nor exposed themselves to contagion. Why have 
they this fear? It is because their forbidden sexual feelings have been aroused and with the wish comes the fear of consequences. So it is not quite so much the fear that they have the disease as the fear of the impulses which, if they gratify them, may lead to the horrible diseases of which they have heard in their boyhood. It is only when it is analysed out that they see the mechanism, and that the terrors they have been threatened with are nonsense, the relics of old forgotten fears.

Even, therefore, those who have not exposed themselves to infection, and have been assured they have no infection, may yet have fear of infection. Why? The reason is that they have had these old fears of an earlier day, and these fears have surged up into consciousness, with the arousing even of a forbidden wish ; so the old fears have come up as an obsession, a phobia.

Another point is that these people often have a sense of guilt: that is to say, the ordinary person might expose himself to infection: he goes to a doctor, is examined, is reassured and is happy about it and no more is heard of him. In the case of the person who continues to have this fear and this sense of guilt, it is not a fear of what he has done, but of his guilt and its consequences. He has not solved the problem ; he goes on saying, "I shall do what I want to," and then there comes the fear of consequences ; every time the self-willed impulse comes up the phobia returns.

I will close by relating one other case to illustrate these points. He was a man, aged twenty-six, and had never previously had sex relations. His initiation of such relations was with his uncle's mistress, who later became the latter's wife. He had sex relations with her once or twice, largely at the instigation of the lady, and then had a fear that he had syphilis; and, though reassured, he still had the idea. In that case there was also a more generalised fear, that of illness. In his infancy he had a very drunken and cruel father, who not only terrified him, but also deliberately ill-treated him. On one occasion, when drunk, he nearly strangled the child to death. That filled him with a great terror, and a feeling of strong defiance against his father. Then comes the precipitating cause. His uncle was closely identified with his father; they were in business together, and 
were very like each other in character and disposition; therefore when he had sex relations with his uncle's mistress it was not merely a sexual matter, but also an act of defiance of his father and his authority. So the self-will element came in. But immediately after the act he had a terror of the consequences, as of his father in childhood, and this fear naturally took the form of fear of syphilis.

So I hope you see, ladies and gentlemen, that these cases of syphilophobia and other phobias are complicated and difficult to deal with. In mild cases sometimes reassurance following a negative result of tests will cure them, but in some cases neither persuasion, suggestion nor hypnotism will do good, and it is necessary to go deeply into the case by analysis. When there is this definite and deep-seated fear, it can be projected in almost any form. It does not matter to us psychologists whether it is projected on to general illness, or cancer, or syphilis, because the form it takes is insignificant in comparison with the real fear which underlies it, namely, the person's fear of his own forbidden impulses, which force him into situations the consequences of which he dreads; that is the secret source of neurotic fears. 